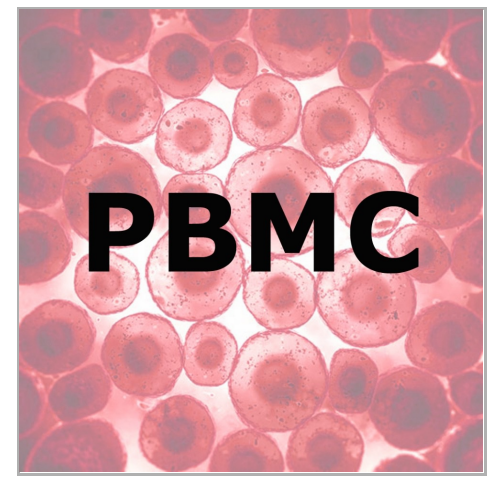

VERSION 1

JUL 23, 2020

\section{open $\boldsymbol{\sigma}$ ACCESS}

DOI:

dx.doi.org/10.17504/protocol s.io. biw 2 kfge

Protocol Citation: Marco Cosentino, Elisa Storelli, Alessandra Luini, Massimiliano LM Legnaro, Emanuela Rasini, Marco Ferrari, Franca Marino 2020. PBMC- 01a - Isolation of Human PBMC from Buffy Coat. protocols.io

https://dx.doi.org/10.17504/p rotocols. io. biw $2 \mathrm{kfge}$

License: This is an open access protocol distributed under the terms of the Creative Commons Attribution License, which permits unrestricted use, distribution, and reproduction in any medium, provided the original author and source are credited

Protocol status: Working We use this protocol and it's working

Created: Jul 23, 2020

Last Modified: Jul 23, 2020

PROTOCOL integer ID: 39610

\section{(3) PBMC- 01 a - Isolation of Human PBMC from Buffy Coat V.1}

Marco Cosentino ${ }^{1}, \quad$ Elisa Storelli ${ }^{1}$, Alessandra Luini ${ }^{1}$, Massimiliano LM Legnaro ${ }^{1}$, Emanuela Rasini ${ }^{1}$, Marco Ferrari ${ }^{1}$, Franca Marino ${ }^{1}$ ${ }^{1}$ Center for Research in Medical Pharmacology, University of Insubria
(Varese, Italy)

(2) Farmacologia Medica

\section{ABSTRACT}

\section{List of published work using this protocol}

- Kustrimovic, N., Comi, C., Magistrelli, L., Rasini, E., Legnaro, M., Bombelli, R., Aleksic, I., Blandini, F., Minafra, B., Riboldazzi, G., Sturchio, A., Mauri, M., Bono, G., Marino, F., \& Cosentino, M. (2018). Parkinson's disease patients have a complex phenotypic and functional Th1 bias: cross-sectional studies of CD4+ Th1/Th2/T17 and Treg in drug-naiive and drug-treated patients. Journal of neuroinflammation, 15(1), 205. https://doi.org/10.1186/s12974-018-1248-8

- Kustrimovic, N., Rasini, E., Legnaro, M., Bombelli, R., Aleksic, I., Blandini, F., Comi, C., Mauri, M., Minafra, B., Riboldazzi, G., Sanchez-Guajardo, V., Marino, F., \& Cosentino, M. (2016). Dopaminergic Receptors on CD4+ T Naive and Memory Lymphocytes Correlate with Motor Impairment in Patients with Parkinson's Disease. Scientific reports, 6, 33738. https://doi.org/10.1038/srep33738

- Cosentino M., Ferrari M., Kustrimovic N., Rasini E., Marino F. (2015). Influence of dopamine receptor gene polymorphisms on circulating $\mathrm{T}$ lymphocytes: A pilot study in healthy subjects. Human immunology, 76, 10, 747-752.

https://doi.org/10.1016/j.humimm.2015.09.032 
Keywords: PBMC, Buffy Coat, Neuroimmune-Pharmacology, Parkinson's Disease, Cell isolation, Primary cell culture
MATERIALS

MATERIALS

88 Fetal bovine serum (FBS) BioWest Catalog \#S181B-500

88 Ficoll Paque PLUS Ge Healthcare Catalog \#17144003-500 ml

88 RPMI 1640 EuroClone Catalog \#ECM 0495L- 500 ml

\& Trypan Blue Solution 0.4\% Thermo Fisher Scientific Catalog \#15250061

Instrumentation required:

- Laminar flow hood

- Optical Microscope (manual cell count)

\section{BEFORE START INSTRUCTIONS}

If you need to obtain PBMC for cell culture, make sure you are using sterile PBS, culture medium, filtered Lysis Buffer and sterile plastic disposables as well. Moreover, work under laminar flow hood when you are processing samples. Otherwise, use non-sterile solutions and plastic disposables, and process samples in cell isolation laboratory.

\section{ALL REAGENTS USED IN THIS PROTOCOL MUST BE AT ROOM TEMPERATURE!}

1 Put the needed amount of blood sample from buffy coat into a $50 \mathrm{ml}$ conical tube.

2 Add an equal volume of PBS $\mathbf{1 X}$ and mix well.

\section{Document}

NAME

SOLUTION- 02 - Phosphate Buffered Saline (PBS)

CREATED BY

Elisa Storelli

\section{PREVIEW}


3 Place $\triangle 3 \mathrm{~mL}$ of FICOLL in a $15 \mathrm{~mL}$ conical tube.

4 CAREFULLY layer $\triangle 12 \mathrm{~mL}$ of diluted blood on the FICOLL with a glass Pasteur Pipette to a 1 final volume of $15 \mathrm{ml}$ as shown in the figure below.

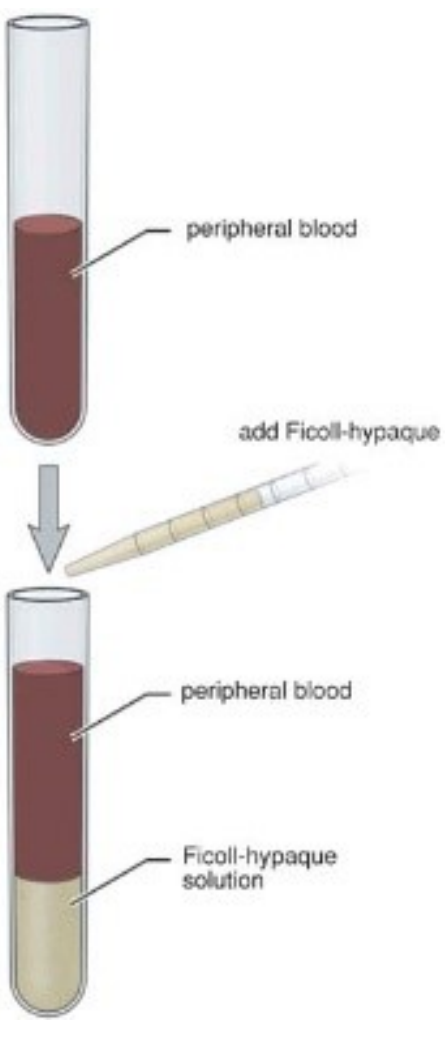

$5 \quad$ Centrifuge samples $\because: 400 \times \mathrm{g}, 00: 40: 00$ without break.

\section{Equipment}

Allegra AVANTI 30

Centrifuge

Beckman Coulter

Beckman Italy 
6 After centrifugation, take out the tubes carefully to not disturb the mononuclear cell layer that appears as a white, cloudy band between the plasma and FICOLL as shown in the figure below.

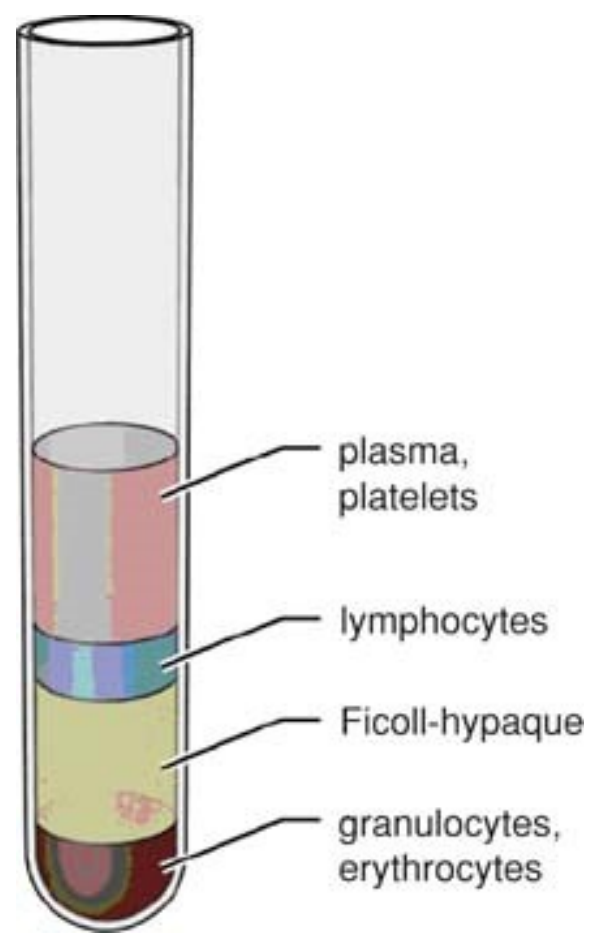

7 Carefully with a glass Pasteur pipette transfer mononuclear lymphocyte cell layer to another 15 $\mathrm{ml}$ conical tube.

8 Wash the isolated PBMC with PBS/FBS $2 \%$ to a final volume of $\triangle 10 \mathrm{~mL}$ and centrifuge at $300 \times \mathrm{g}, 00: 10: 00$ at RT.

Document

NAME

SOLUTION- 05 - Wash solution (PBS/FBS) for PBMC

CREATED BY

Elisa Storelli 


\section{Equipment}

Allegra AVANTI 30

Centrifuge

Beckman Coulter

Beckman Italy

9 Remove supernatants, resuspend pellet in $\triangle 1 \mathrm{~mL}$ of Lysis Buffer and add another $\triangle 9 \mathrm{~mL}$ of Lysis Buffer. Immediately centrifuge the tubes at $\because 100 \times \mathrm{g}, 00: 10: 00$ at RT.

Document

NAME

SOLUTION- 06 - Lysis Buffer

CREATED BY

Elisa Storelli

\section{Equipment}

Allegra AVANTI 30

NAME

Centrifuge

Beckman Coulter

BRAND

Beckman Italy 
10 Remove supernatant and resuspend pellet in $810 \mathrm{~mL}$ PBS/FBS 2\% and centrifuge at $\therefore 300 \times \mathrm{g}, 00: 10: 00$ at RT.

\section{Document}

NAME

SOLUTION- 05 - Wash solution (PBS/FBS) for PBMC

CREATED BY

Elisa Storelli

\section{Equipment}

\section{Allegra AVANTI 30}

NAME

Centrifuge

Beckman Coulter

Beckman Italy

11 Remove supernatant and resuspend the obtained pellet in counting. 


\section{Document}

NAME

SOLUTION- 04 - Wash solution (RPMI/FBS) for PBMC

CREATED BY

Farmacologia Medica

PREVIEW

12 For manual cell count use Türk solution for checking purity.

Mix $10 \mu \mathrm{l}$ of cell suspention with an equal amount of Türk solution (dilution factor $=2$ ), allow mixture 3 min at room temperature.

Take $10 \mu$ l of the mixture and place it inside a Bürker chamber and view under an optical microscope using 40X magnification.

Count the cells in each square found in the four corners and in the central square (see figure 1 below), including those

that lie on the bottom and left-hand perimeters, but not those that lie on the top and right hand perimeters (see figure

2 below).

Total number of cells per $\mathrm{ml}=$ mean number of cells $\mathrm{x}$ dilution factor $\mathrm{x} 104$ (hemacytometer volume). 


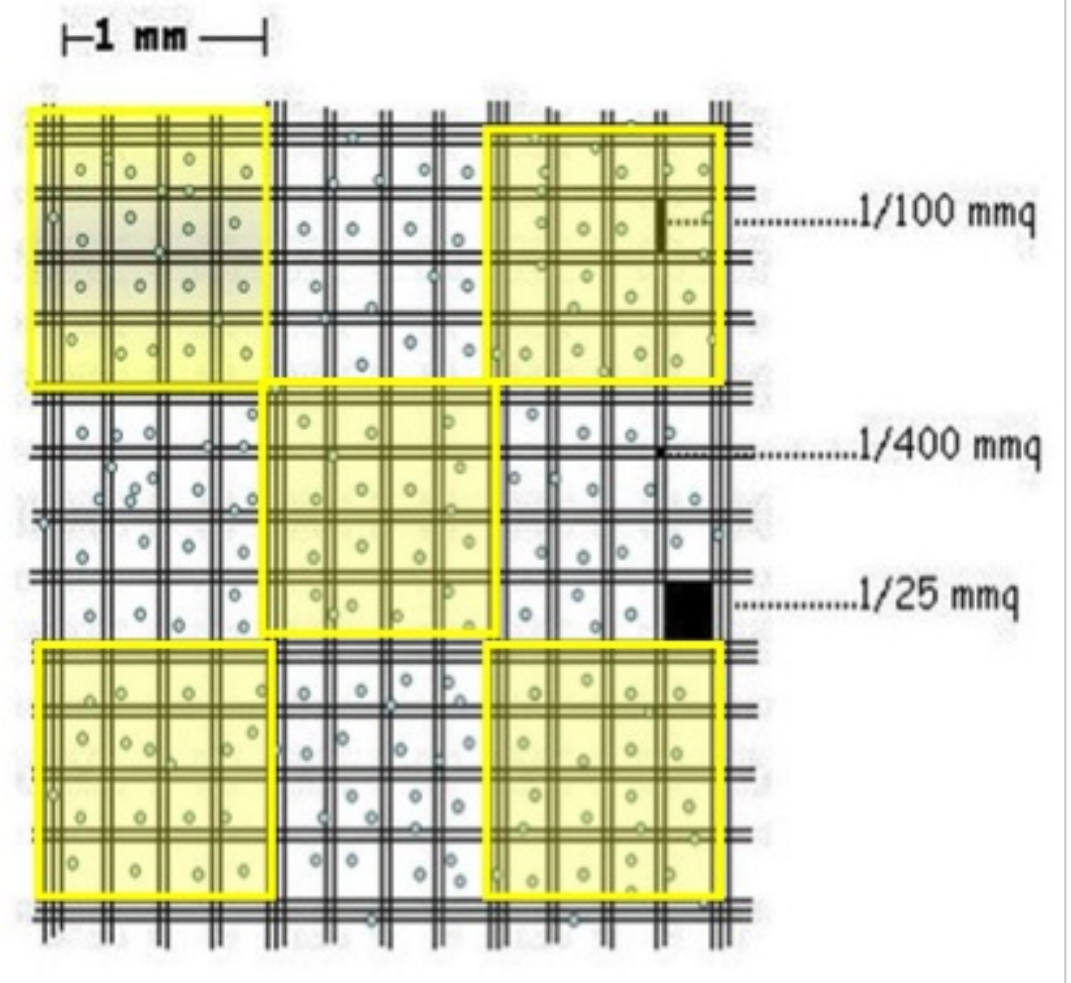

Figure 1

The gridded area of the chamber consists of nine $1 \mathrm{mmq}$ squares. These squares are subdivided in three directions; $0.0625 \mathrm{mmq}, 0.05 \mathrm{mmq}$ and $0.04 \mathrm{mmq}$. The central square here in Figure 1 is further subdivided into $0.0025 \mathrm{mmq}=1 / 25 \mathrm{mmq}$ squares. Count cells in 5 squares as shown. 


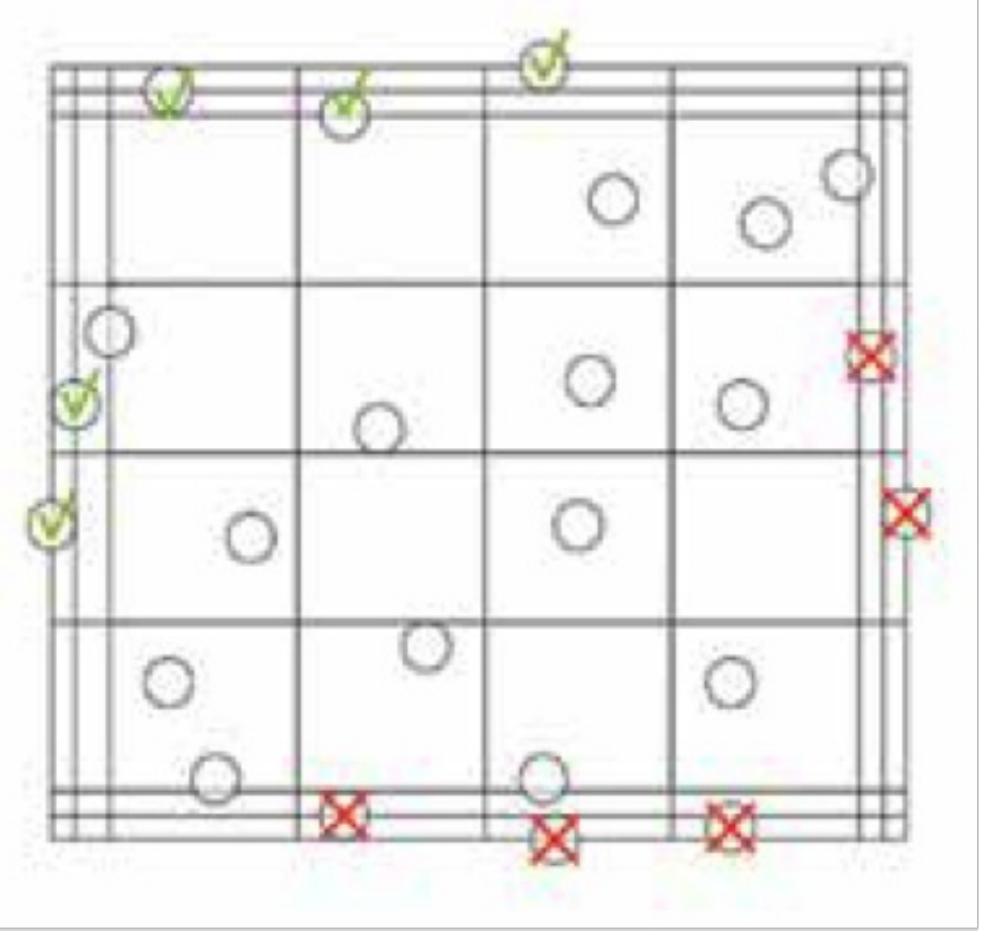

Figure 2

Concerning those cells that lay on the perimeter of the square, count following this scheme.

Document

NAME

SOLUTION- 08 - Türk solution

CREATED BY

Farmacologia Medica

\section{OPTIONAL STEP}

For automatic cell count with Cellometer machine use Trypan Blue.

The machine will calculate the $n^{\circ}$ of cells $/ \mathrm{ml}$ and the $\%$ of viability.

Take $\triangle 10 \mu \mathrm{L}$ of cell suspention and add an equal amount of Trypan Blue. Use all the volume to place it in a counting chamber. Place the chamber inside Cellometer and count. 


\section{Equipment}

\section{Cellometer Auto T4}

Automated cell counter

Nexcelom Bioscience

EuroClone

\section{Document}

\section{NAME}

\section{SOLUTION- 09 - Trypan Blue solution}

CREATED BY

Farmacologia Medica

14 If needed, check the purity of PBMC suspension by using morphological parameter of the flow cytometer.

For this test $0.5 \times 10^{6} \mathrm{PBMC}$ in $500 \mu$ of PBS are enough.

\section{Equipment}

BD FACS Celesta

Flow Cytometer

Becton Dickinson 
15 Expected results

Expected result

VIABILITY - The expected viability by Trypan Blue should be $\geq 90 \%$.

PURITY - The PBMC suspension obtained should contain at least $80 \%$ of lymphocytes, 10 $15 \%$ of monocytes and few contaminant PMN cells $(\leq 5 \%)$ as confirmed by flow cytometry.

YIELD - The expected amount of PBMCs should be $\pm 100 \times 10^{6}$ starting from $25 \mathrm{ml}$ of buffy coat. 